\title{
Relevance of tumor angiogenesis patterns as a diagnostic value and prognostic indicator in oral precancer and cancer
}

This article was published in the following Dove Press journal:

Vascular Health and Risk Management

26 January $201 \mathrm{I}$

Number of times this article has been viewed

\author{
Devi Charan Shetty' \\ Puneet Ahuja ${ }^{2}$ \\ DK Taneja ${ }^{5}$ \\ Ajit Singh Rathore ${ }^{2}$ \\ Shivjot Chhina ${ }^{3}$ \\ Upasana Sethi Ahuja ${ }^{4}$ \\ Kiran Kumar' \\ Anshuman Ahuja ${ }^{5}$ \\ Priyanka Rastogi' \\ 'Department of Oral \& Maxillofacial \\ Pathology, I.T.S-CDSR, Muradnagar, \\ Ghaziabad, Uttar Pradesh, India; \\ 2Department of Oral \& Maxillofacial \\ Pathology; ${ }^{3}$ Department of \\ Periodontics; ${ }^{4}$ Department of Oral \\ Medicine \& Radiology; ${ }^{5}$ Department \\ of Oral \& Maxillofacial Surgery, I.T.S \\ Dental College, Greater Noida, \\ Uttar Pradesh, India
}

Correspondence: Devi Charan Shetty Department of Oral and Maxillofacial Pathology, I.T.S-CDSR, Muradnagar, Delhi Meerut Road, Ghaziabad-201206, India Tel+9l 9873525076 Email shettydivya76@rediffmail.com

\begin{abstract}
Tumor angiogenesis occurs by recruitment of endothelial cell precursors or by sprouting of existing capillaries, which differ from the normal vasculature by having an altered morphology that can be exploited for diagnosis and as a prognostic indicator. Improved technologies have propelled diagnosis into a new era. These technologies have to be used with great precision. The diagnosis of a dysplastic premalignant lesion of the oral mucosa cannot be based solely on clinical findings. Therefore histologic evaluation of a representative biopsy specimen is necessary. Accurate judgment of the proper site for biopsy is essential for reaching a correct diagnosis. The aim of this report is to analyze the vascular patterns with the help of direct oral microscopy and the technique of stereo-optical microscopy in the oral cavity to select biopsy sites, and compare the outcome of a directed biopsy with that of biopsy specimens obtained from sites selected solely on the basis of clinical criteria. The study sample comprised 50 oral mucosal lesions. A statistically significant difference was noted between samples judged to be microscopically representative sites. We conclude that this method would aid in early and better diagnosis and treatment planning of oral premalignant and malignant lesions by assessing the various vascular patterns in the mucosa.
\end{abstract}

Keywords: stereomicroscope, biopsy site selection, angiogenesis, colposcopy

\section{Introduction}

Angiogenesis is a term that implies the formation of new micro-vessels from differentiated endothelium. Tumor angiogenesis occurs by recruitment of endothelial cell precursor or by sprouting of existing capillaries as in physiologic angiogenesis. However, tumor blood vessels differ from the normal vasculature by having altered morphology which can be exploited for diagnosis and as a prognostic indicator.

The diagnosis of a dysplastic premalignant lesion of the oral mucosa cannot be based solely on clinical findings. Therefore histologic evaluation of a representative biopsy specimen is necessary. ${ }^{1}$

In the oral cavity a white patch or ulcero-proliferative growth has varied differential diagnoses ranging from hyperkeratoses, premalignant lesion (leukoplakia), to frank carcinoma. ${ }^{2}$ An erythematous lesion, homogeneous or not, is considered to be more likely to become malignant than are whitish lesions. ${ }^{1-7}$ Oral lichen planus has also been suggested to show a certain percentage of malignant transformation. ${ }^{8,9}$

Dysplasia and carcinoma in situ herald invasive oral cancer, ${ }^{5,7}$ but carcinomas also occur in areas which were previously apparently normal (not dysplastic).,

No reliable method applicable to the oral cavity can yet replace a biopsy for a more definitive diagnosis of oral cancer. However, a few adjuncts can be used. Exfoliative 
cytology carries the risk of false-positive or false-negative results and a biopsy is always necessary for final diagnosis. Toluidine blue may be used to identify a suitable site for biopsy, but carries the risk of false-positive staining. ${ }^{10}$

Histologic assessment of a biopsy specimen is regarded as the most reliable criterion for a correct diagnosis; consequently, the specimen must be taken from the most representative area. Light microscopy has been used in the field of oral pathology for histopathological evaluation of biopsy specimens and reaching at an accurate diagnosis. Apart from this application, this tool of immense potential has been put to little use. Stereomicroscopy has been utilized lately and has been shown to give easy visualization of the work area. ${ }^{11}$

The aim of this report is to analyze the vascular patterns with the help of direct oral microscopy and the technique of

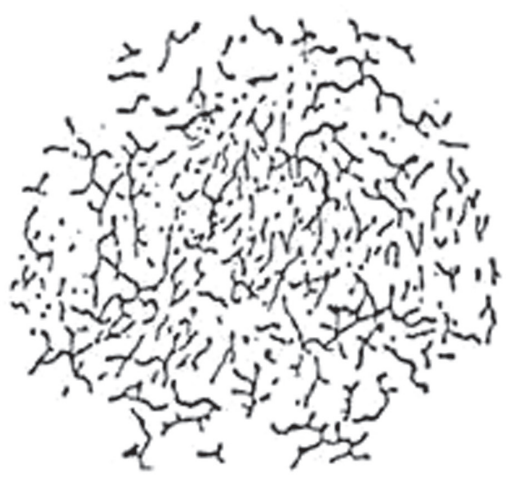

A

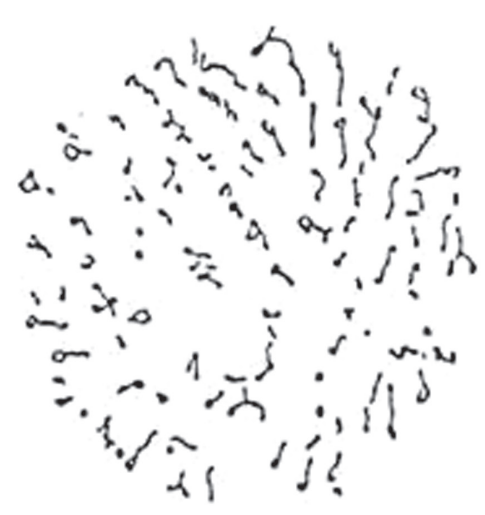

C

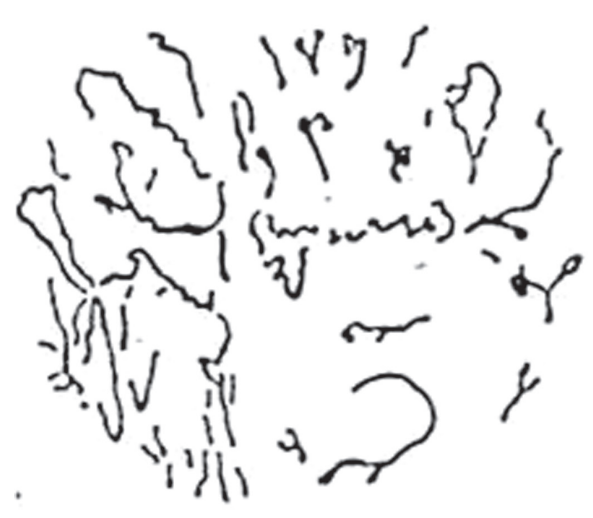

E
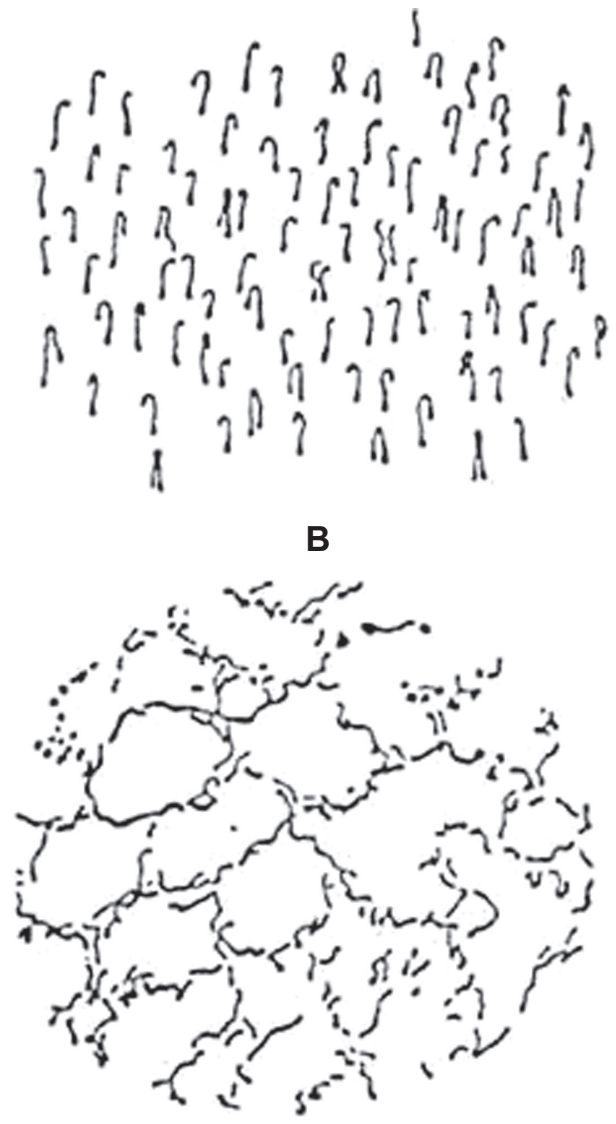

D

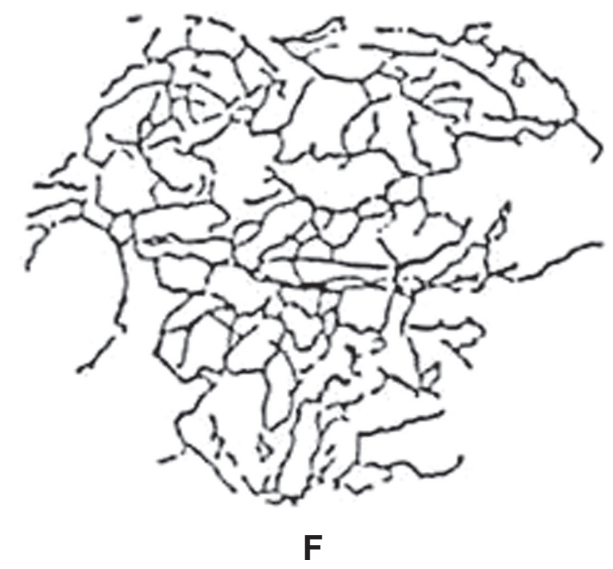

Figure I A) Network capillaries; B) hairpin capillaries; C) punctation capillaries; D) mosaic capillaries; E, F) atypical capillaries. 
stereo optical microscopy in the oral cavity to select biopsy sites, and compare the outcome of a directed biopsy with that of biopsy specimens obtained from sites selected solely on the basis of clinical criteria.

\section{Materials and methods}

\section{Patient selection and clinical examination}

Patients referred to the Department of Oral and Maxillofacial Pathology of I.T.S-CDSR, Muradnagar, Ghaziabad, India for diagnosis and treatment of oral mucosal lesions participated in the present study. A total of 50 patients (Table 1) who participated were clinically evaluated and provisional diagnoses of lichenoid lesion, leukoplakia, erythroplakia, and frank carcinoma were made.

\section{Instrumentation and methodology of screening}

The oral mucosa of participating patients was clinically analyzed. An optimum site for biopsy was determined and marked. A stereozoom binocular microscope (Model no. SZMBC-1; Leica Microsystem, Wetzlar, Germany) with a mobile floor stand on four castor wheels for easy handling and absolute stability and a CCD digital camera attachment was then used to analyze the mucosal lesions. Varied vascular patterns were recognized and labeled according to the criteria for vascular changes.

\section{Criteria for vascular changes}

The vascular changes described in colposcopic literature were used as the criteria for selecting biopsy sites in the oral cavity. These include the vascular pattern, intercapillary distance, surface pattern, color tone, and opacity, as well as the clarity of demarcation of the mucosal lesions..$^{12,13}$

Two basic types of capillary network can be seen with direct microscopy (ie, colposcopy): network capillaries and hairpin capillaries (Figure 1A, B). ${ }^{13}$ In dysplasia and carcinoma in situ, a specific vascular pattern, punctation (previously called ground) is common (Figure 1C). Punctation is characterized by dilated, often twisted, irregular, hairpin-type vessels. Another pattern of the vessels in dysplasia is called mosaic (Figure 1D). Like punctation vessels, true mosaic vessels are usually seen in sharply demarcated areas. When it is difficult to describe the pattern of the vessels, the term atypical vessels is used (Figure 1E, F). Capillary punctation, mosaic, or atypical patterns are encountered in malignant lesions. Therefore, the presence of one of these indicates the need for biopsy and histopathologic examination. ${ }^{13}$
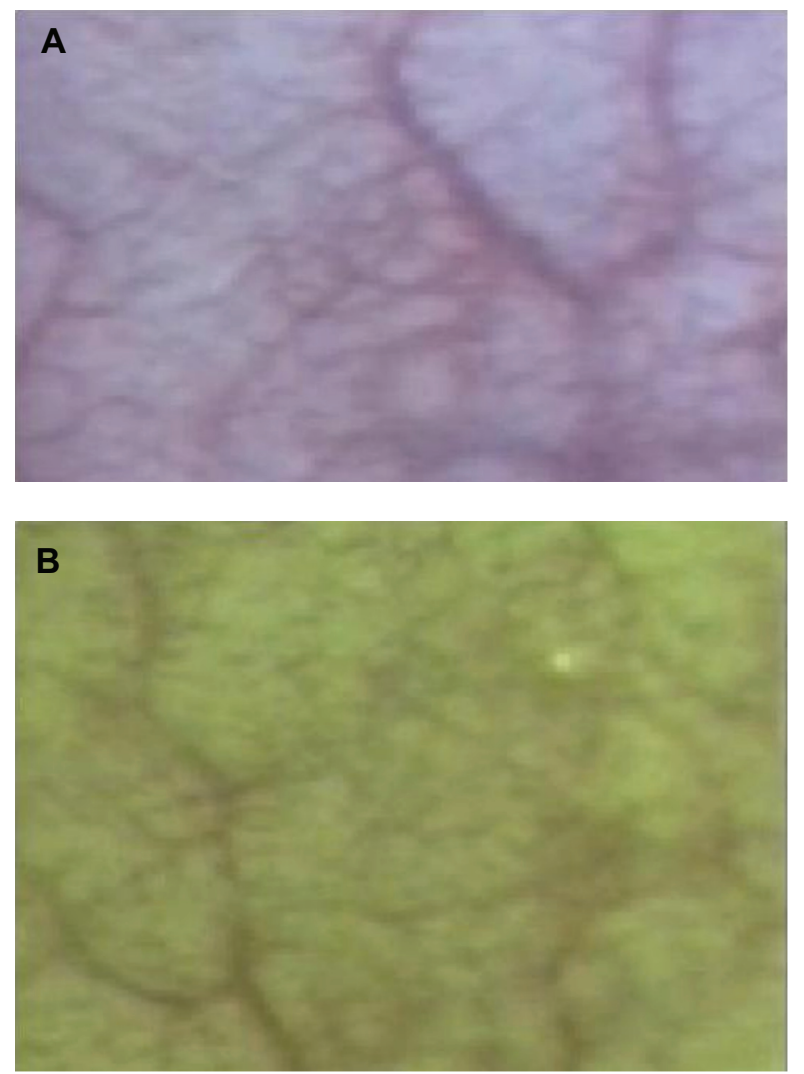

Figure 2 A) Photomicrograph depicting network capillary pattern (stereomicroscope, autozoom $\times 40$ ). B) Photomicrograph depicting network capillary pattern (stereomicroscope using green filter, autozoom $\times 40$ ).

Varied vascular patterns appreciated on mucosal lesion analyses were labeled as per the aforementioned criteria (Figures 2A, 2B, 3, 4, 5).

\section{Histological analysis}

Formalin-fixed sections, $3 \mu \mathrm{m}$ thick and stained with hematoxylin and eosin (H\&E) and periodic acid-Schiff(PAS), were histopathologically evaluated by one of the authors.

\section{Statistical analysis}

The 2-sided binomial test was used for the statistical analysis.

\section{Results}

\section{Clinical examination}

The 50 oral mucosal lesions were first diagnosed clinically as different types of lichenoid (including lichen planus) lesions (17 patients), homogeneous leukoplakia (11 patients), or suspected malignancy (ie, nonhomogeneous leukoplakia or carcinoma [22 patients]). The locations of the lesions are shown in Table 2. 


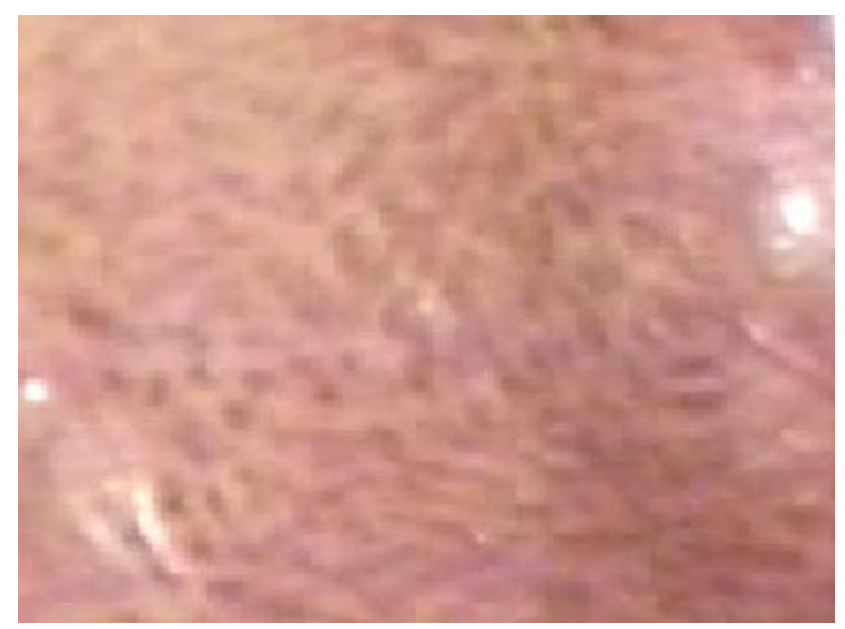

Figure 3 Photomicrograph depicting punctuate capillary pattern (stereomicroscope using green filter, autozoom $\times 40$ ).

\section{Direct oral microscopy}

Thirty-nine of the patients (78\%) showed changes in the vascular picture on microscopy. Twenty of these had punctation vessels (Figure 1A), 7 had mosaic vessels (Figure 1B), and 12 had atypical vessels (Figure 1C). The other lesions showed a normal capillary network. In all patients, the surface pattern, color tone, opacity, and clarity of demarcation were more easily seen with microscopy than when they were compared on routine clinical examination.

\section{Histopathologic diagnosis and its relation to clinical and direct oral microscopic diagnoses and selection of biopsy sites}

In all 17 patients with a clinical diagnosis of lichenoid lesions the diagnosis was verified by histologic examination. In 12 patients, the histologic changes showed more severe dysplasia or less differentiation in the biopsy specimens

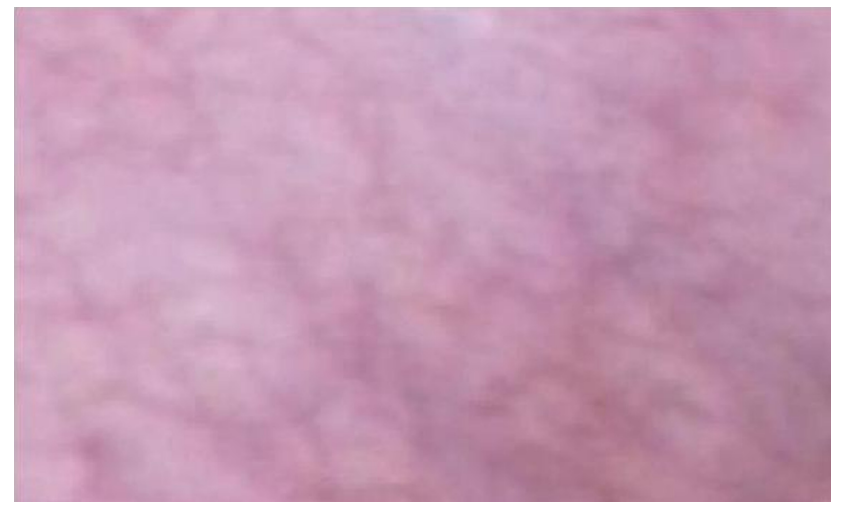

Figure 4 Photomicrograph depicting mosaic capillary pattern (stereomicroscope using green filter, autozoom $\times 40$ ).

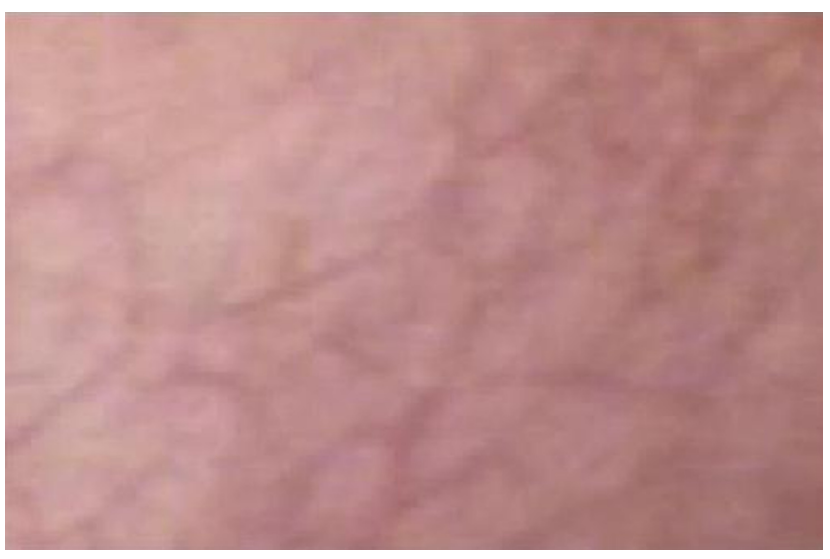

Figure 5 Photomicrograph depicting atypical capillary pattern (stereomicroscope using green filter, autozoom $\times 40$ ).

obtained by direct oral microscopy (Figures 6-9), whereas this was true in only 3 samples obtained after the routine clinical examination. Two patients had no histologic differences between the samples.

None of the 11 patients with a clinical diagnosis of homogeneous leukoplakia showed histologic signs of epithelial dysplasia. Moreover, none showed histologic differences between the biopsy specimens obtained by direct oral microscopy and those from clinical examination.

All 22 patients with a suspected malignancy on the clinical examination had a histologic diagnosis of epithelial dysplasia (11 patients), carcinoma in situ (4 patients), or squamous cell carcinoma (7 patients). Fourteen patients had more extensive cytologic and structural abnormalities in the biopsy specimens obtained by direct oral microscopy, but 3 patients had more extensive changes in the specimen obtained after routine clinical examination. Five patients had no histologic differences between the specimens.

In a total of 26 patients (52\%), the biopsy specimens selected with direct oral microscopy appeared to be more representative of the histologic findings than those selected with routine clinical examination $(0.01, P \leq 0.05)$.

\section{Discussion}

The field of ophthalmology utilizes high magnification microscopes to see minute capillary changes to aid in accurate diagnosis and treatment planning. In gynecology, microcolpohysteroscopy and colposcopes have been used for decades. With the help of papinucoulou smears from the visualized sites an early diagnosis and adequate follow up of cervical cancers have been possible. This has decreased the incidence of cervical cancers from $40 \%$ to $3 \%$ to $7 \% .^{12-16}$ 
Table I Number, sex ratio, and age of 50 patients with oral mucosal lesions examined clinically and with direct microscopy

\begin{tabular}{lllll}
\hline & Lichenoid lesions & Homogeneous leukoplakia & $\begin{array}{l}\text { Nonhomogeneous } \\
\text { leukoplakia/carcinoma }\end{array}$ & \multicolumn{1}{c}{ Total } \\
\hline Patients & 17 & 11 & 22 & 50 \\
Men/women & $7 / 10$ & $7 / 4$ & $12 / 10$ & $26 / 24$ \\
Age (yrs) mean, range & $62,45-71$ & $53,37-64$ & $66,40-86$ & $60,37-86$ \\
\hline
\end{tabular}

Staining with toluidine blue is probably the most common technique used today for early detection of oral cancer in patients at risk and for use as an aid in selecting the exact sites for biopsy and surgery. ${ }^{10,17-21}$ Unlike direct oral microscopy, toluidine blue does not need expensive equipment and is therefore much simpler and less costly, but the risk of false-positive staining can be as high as $30 \%{ }^{10}$ Questions have also been raised about the risks associated with the use of toluidine blue because it shows an affinity for DNA. ${ }^{22}$

Evidence-based recommendations for mass screening for oral precancer and cancer have been laid out, which highlight the use of newer techniques. Devices like ViziLite ${ }^{\circledR}$ Plus (Zila Inc., Scottsdale, AZ) and Orascoptic (Middleton, WI) utilize the property of tissue reflectance, whereas devices like VELscope $^{\circledR}$ (LED Dental Inc, Burnaby, BC, Canada) based on autofluorescence, are marketed as an adjunct to visual examinations in the identification of oral mucosal abnormalities. ${ }^{23}$

Capillary changes precede tumor growth, with the pattern of tumor angiogenesis being different from the usual neovascularization taking place during repair and regeneration procedures. At a cellular level various molecules such as vascular endothelial growth factor, basic fibroblast growth factor, and transforming growth factor alpha are implicated, but the clinical perceptibility of these altered vascular patterns is poor. Direct optical visualization of these patterns would be helpful in early determination of the underlying pathology and also aid in marking out the site for biopsy.

It is not possible to determine the progression of dysplasia to carcinoma on the basis of clinical findings.

Table 2 Locations of oral mucosal lesions in 50 patients

\begin{tabular}{llll}
\hline Location & $\begin{array}{l}\text { Lichenoid } \\
\text { lesions } \\
(\mathbf{n}=\mathbf{I 7})\end{array}$ & $\begin{array}{l}\text { Homogeneous } \\
\text { leukoplakia } \\
(\mathbf{n}=\mathbf{I} \mathbf{)})\end{array}$ & $\begin{array}{l}\text { Nonleukoplakia/ } \\
\text { carcinoma } \\
(\mathbf{n}=\mathbf{2 2})\end{array}$ \\
\hline Cheek & 10 & 5 & 9 \\
Tongue & 5 & 3 & 3 \\
Gingiva & 0 & 2 & 3 \\
Floor of mouth & 0 & 1 & 4 \\
Lips & 2 & 0 & 2 \\
Soft palate & 0 & 0 & 1 \\
\hline
\end{tabular}

Regular follow-up examinations are therefore essential for precancerous lesions, such as nonhomogeneous leukoplakia.

In the present study we found out that the biopsy specimens selected with direct oral microscopy appeared to be more representative of the histologic findings than those selected with routine clinical examination. The altered vascular patterns definitely helped with the correct selection of the site for biopsy, which in turn helped us reach a more definitive diagnosis, thus avoiding false-negative results.

Hopefully, direct oral microscopy will be used to follow mucosal lesions and detect signs of progression because at present this seems to be the only way to evaluate vascular changes in the oral mucosa. Compared with staining with toluidine blue, this may be the main advantage of using direct oral microscopy. The chief disadvantages are the complexity and cost, and these should be evaluated by further comparative studies. This complex diagnostic methodology would, in the future studies, require analysis on a larger sample size with added filter modifications for typifying exact vascular pattern modifications. The finesse of judgment should not be compromised owing to the time factor, while screening large population. However the cost of the equipment is not a big

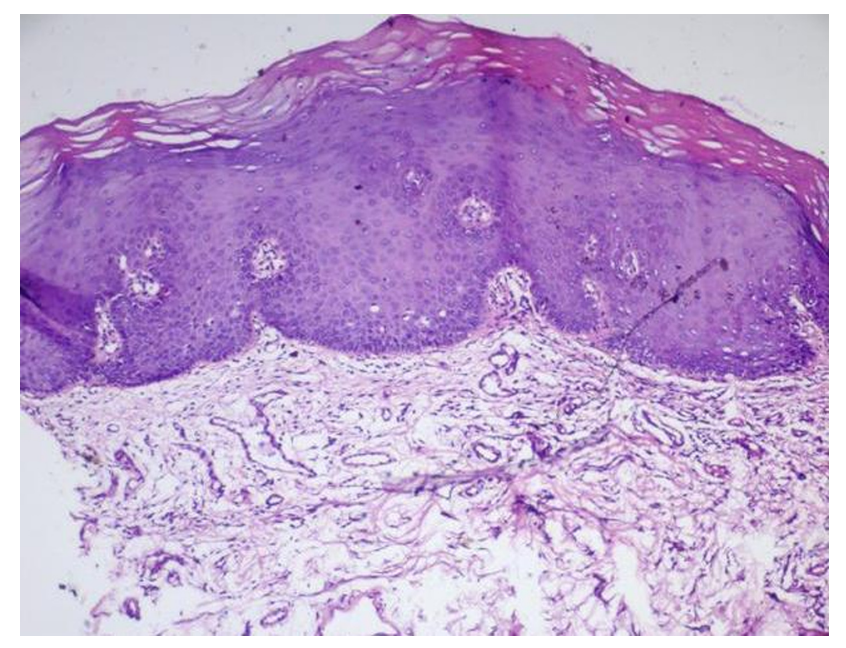

Figure 6 Photomicrograph depicting mild dysplasia in a lesion. Specimen taken after direct clinical examination $(\mathrm{H} \& \mathrm{E}$, magnification $\times 10)$. 


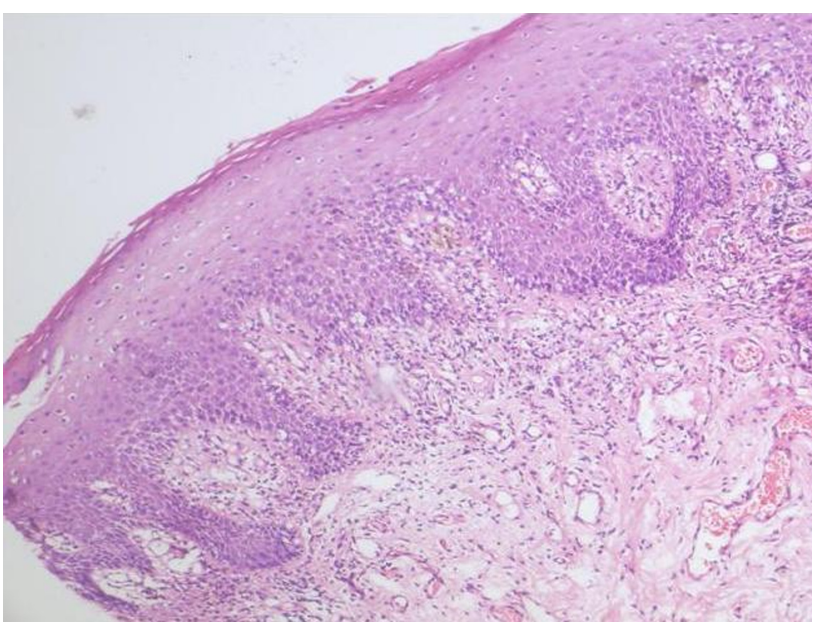

Figure 7 Photomicrograph depicting moderate dysplasia in a lesion. Specimen taken after stereo-optical examination $(\mathrm{H} \& \mathrm{E}$, magnification $\times \mathrm{I0})$.

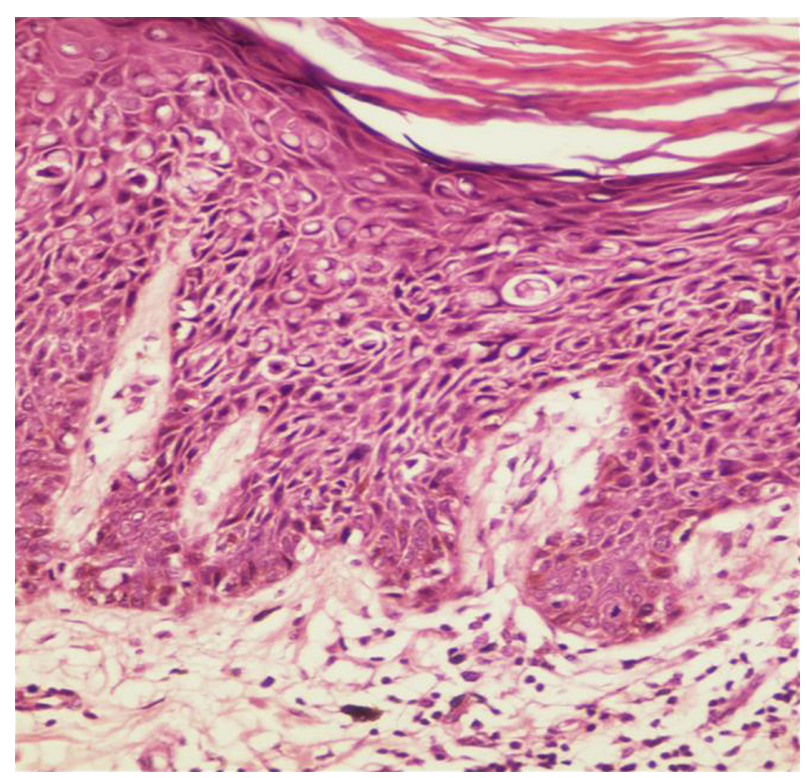

Figure 8 Photomicrograph depicting severe dysplasia in a lesion. Specimen taken after stereo-optical examination ( $\mathrm{H} \& \mathrm{E}$, magnification $\times 40)$.

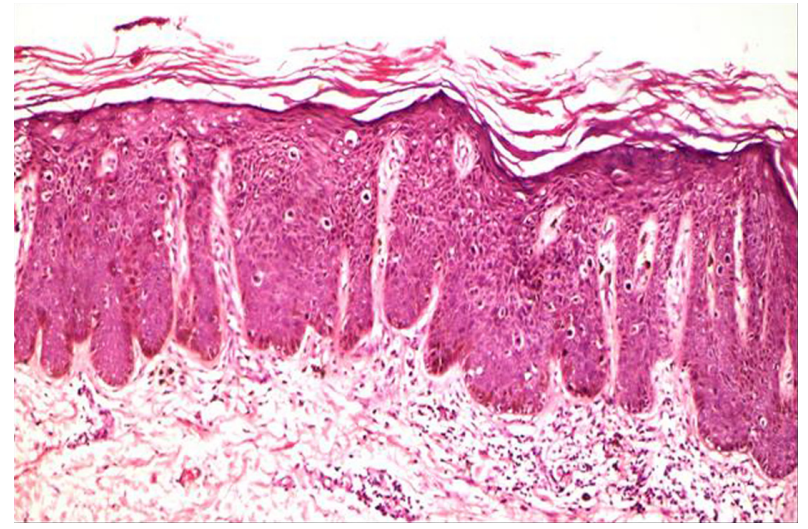

Figure 9 Photomicrograph depicting carcinoma in situ in a lesion. Specimen taken after stereo-optical examination $(\mathrm{H} \& \mathrm{E}$, magnification $\times 10)$. drawback compared to its advantage in terms of visualization and precision in clinical diagnosis.

The question remains of whether the advent of such microscope-aided precision dentistry equipment in dentistry heralds the end of direct visualization/naked eye working. The advantage would be better selection of the biopsy site compared with naked eye selection, which would help improve diagnosis and treatment planning of oral premalignant and malignant lesions.

\section{Disclosure}

The authors declare no conflicts of interest.

\section{References}

1. Axell T, Holmstrup P, Kramer IRH, Pindborg JJ, Shear M. International seminar on ia and associated lesions related to tobacco habits. 1983 June 27-30; Lund University, Malmö, Sweden. Community Dent Oral Epidemiol. 1984;12:144-154.

2. Shafer WG, Hine MK, Levy MB. A Textbook of Oral Pathology, Fifth ed. Philadelphia: WB Saunders; 2006.

3. Pindborg JJ, Jost O, Renstrup G, Roed-Petersen B. Studies in oral leukoplakia: a preliminary report on the period prevalence of malignant transformation in leukoplakia based on a follow-up study of 248 patients. J Am Dent Assoc. 1968;76:767-771.

4. Mincer HH, Coleman SA, Hopkins KP. Observations on the clinical characteristics of oral lesions showing histologic epithelial dysplasia. Oral Surg Oral Med Oral Pathol. 1972;33:389-399.

5. Bánóczy J, Csiba A. Occurrence of epithelial dysplasia in oral leukoplakia. Analysis and follow-up study of 120 cases. Oral Surg Oral Med Oral Pathol. 1976;42:766-774.

6. Kramer IRH, El-Labban N, Lee KW. The clinical features and risk of malignant transformation in sublingual keratosis. Br Dent J. 1978;144: 171-180.

7. Silverman S Jr, Gorsky M, Lozada F. Oral leukoplakia and malignant transformation. A follow-up study of 257 patients. Cancer. 1984;53: 563-568.

8. Thorn JJ, Holmstrup P, Rindum J, Pindborg JJ. Course of various clinical forms of OLP. A prospective follow-up study of 611 patients. J Oral Pathol. 1988;17:213-218.

9. Holmstrup P, Thorn JJ, Rindum J, Pindborg JJ. Malignant development of lichen planus-affected oral mucosa. J Oral Pathol. 1988;17: 219-225.

10. Silverman S Jr, Dillon WP. Diagnosis. In: Silverman S Jr, editor, Oral Cancer. Third ed. New York: Am Cancer Soc; 1990:41-60.

11. Gynther GW, Rozell B, Heimdahl A. Direct oral microscopy and its value in diagnosing mucosal lesions. Oral Surg Oral Med Oral Pathol Oral Radiol Endod. 2000;90:164-170.

12. L'Estrange P, Bevenius J, Williams L. Intraoral application of microcolpohysteroscopy. A new technique for clinical examination of oral tissues at high magnification. Oral Surg Oral Med Oral Pathol 1989;67: 282-285.

13. Kolstad P. Terminology and definitions. In: Kolstad P, editor. Atlas of Colposcopy. Third ed. London: Churchill Livingstone; 1982: 21-31.

14. Stafl A. Colposcopy. Cancer. 1976;38:432-435.

15. Kirkup W, Singer A, Hill SA. The accuracy of colposcopically directed biopsy in patients with suspected intraepithelial neoplasia of the cervix. Br J Obstet Gynecol. 1980;87:1-4.

16. Baldauf JJ, Dreyfus M, Ritter J, Philippe E. An analysis of the factors involved in the diagnostic accuracy of colposcopically directed biopsy. Acta Obstet Gynecol Scand. 1997;76:468-473. 
17. Mashberg A. Reevaluation of toluidine blue application as a diagnostic adjunct in the detection of asymptomatic oral squamous carcinoma: a continuing prospective study of oral cancer. III. Cancer. 1980;46: 758-763.

18. Rosenberg D, Cretin S. Use of meta-analysis to evaluate tolonium chloride in oral cancer screening. Oral Surg Oral Med Oral Pathol. 1989;67:621-627.

19. Epstein JB, Oakley C, Millner A, Emerton S, van der Meij E, Le N. The utility of toluidine blue application as a diagnostic aid in patients previously treated for upper oropharyngeal carcinoma. Oral Surg Oral Med Oral Pathol Oral Radiol Endod. 1997;83:537-547.
20. Martin IC, Keraval CJ, Reed M. The application of toluidine blue as diagnostic adjunct in the detection of epithelial dysplasia. Oral Surg Oral Med Oral Pathol Oral Radiol Endod. 1998;85:444-446.

21. Mashberg A. Tolonium (toluidine blue) rinse: a screening method for the recognition of oral carcinoma. JAMA. 1981;245:2408-2410.

22. Wysocki GP. Toluidine blue - viewpoints. Oral Surg Oral Med Oral Pathol Oral Radiol Endod. 1999;87:527-528.

23. Rethman MP, Carpenter W, Ezra EW, Cohen, Epstein J, Evans CA, et al. Evidence based clinical recommendations regarding screening of oral squamous cell carcinomas. J Am Dent Assoc. 2010;141:509-520.

\section{Publish your work in this journal}

Vascular Health and Risk Management is an international, peerreviewed journal of therapeutics and risk management, focusing on concise rapid reporting of clinical studies on the processes involved in the maintenance of vascular health; the monitoring, prevention and treatment of vascular disease and its sequelae; and the involvement of metabolic disorders, particularly diabetes. This journal is indexed on PubMed Central and MedLine. The manuscript management system is completely online and includes a very quick and fair peer-review system, which is all easy to use. Visit http://www.dovepress.com/ testimonials.php to read real quotes from published authors.

Submit your manuscript here: http://www.dovepress.com/vascular-health-and-risk-management-journal 